\title{
CONSOLIDATION AND RESTORATION OF HISTORICAL HERITAGE: THE FLAVIAN AMPHITHEATER IN ROME.
}

\author{
S. Podestà ${ }^{1}$, F. Romis ${ }^{2,}$ *, L. Scandolo ${ }^{1}$ \\ ${ }^{1}$ Department of Civil, Chemical and Environmental Engineering, University of Genoa, via Montallegro 1, 16145 Genoa, Italy - \\ (stefano.podesta, lorenzo.scandolo)@unige.it \\ ${ }^{2}$ Department of Civil and Industrial Engineering, University of Pisa, Largo Lucio Lazzarino 2, 56122 Pisa, Italy - \\ federico.romis@ing.unipi.it
}

Commission II - WG II/8

KEY WORDS: Archaeological site protection, Phase of knowledge, Damage analysis, Consolidation and restoration, Retrofitting techniques, Historical analysis

\begin{abstract}
:
The recovery and retrofitting techniques adopted for historical structures and archaeological sites face an apparent dichotomy between conservation of constructions and the safety of users. Literatures show several examples where the current day structural safety of historical constructions, gets defined by the nature of past interventions, the compatibility of materials and elements used in retrofitting. The adopted interventions were, in their time, considered innovative, but over the years their compatibility and reversibility leave the historic constructions structurally vulnerable. For these reasons, a careful understanding of the structural systems is fundamental for the implementation of appropriate retrofitting solutions. Especially for monuments and Archaeological sites the objective to be achieved has to be clear, avoiding destructive investigation tests. In this work the instabilities caused by a consolidation intervention on some travertine columns in a sector of the Flavian Amphitheatre, better known as "Colosseum " in Rome, are critically analysed. The current consolidation operations are compared to the previous one. The restoration activity involves in-depth diagnosis process: the historical analysis of the failures and restorations of that area of the Colosseum, a survey of the crack pattern and an indirect investigation on the travertine of the columns. Subsequently the various data coming from the knowledge phase are elaborated, in order to have a correct interpretation of the causes triggering the failure and guide the choice of the most correct retrofitting techniques.
\end{abstract}

\section{INTRODUCTION}

The knowledge of construction and retrofit techniques, analysed in their historical context, as well their failure mechanisms, is a prerequisite for the protection of monumental buildings and assumes a fundamental role in determining the damages and for planning the retrofit interventions (Giuffré, 1993).

In this sense, the consolidation interventions adopted mirror the technical knowledge of their respective periods. The disaster events that hit the Italian territory in recent years highlighted different critical aspects of these interventions, carried out in the past, in terms of ineffectiveness or even their harmfulness (Borri et al., 2018). The main problem in those cases, given the limited computational possibilities, was the desire to make the structure similar to the calculation model, therefore incompatible materials were introduced for the structure strengthening (D'Altri et al., 2019). This aspect is even more critical in case of monumental buildings or archaeological sites, where even the modifications and the changes occurred during the centuries are difficult to detect, because involve the superposition of different materials and construction technologies, the alteration of the structural homogeneity and the differences in realization respect to the original design. The structural safety is, therefore, influenced by the conservation of the architectural profile and morphology of the structure.

The modern interventions to conserve a monument are currently calibrated to ensure three important parameters, like reversibility, durability and preservation of the architectural integrity. If technical knowledge can limit the consolidation intervention, a reversible operation is carried out, which can therefore resolve the problem immediately, but can also be altered over time, employing materials that are durable or easily replaced when they lose their original purpose (MIBACT, 2010).

All these aspects are highlighted and have been addressed in the intervention summarized in the following article, where the instabilities caused by a consolidation intervention on six travertine columns in a section of the Flavian Amphitheatre, better known as "Colosseum" in Rome, are critically analysed. The columns are located near the historical entrance on the east side of the monument, as shown in Figure 1 and Figure 2. In order to define the cause that led to the current damage typology detected, the history of the past damages and retrofit interventions were examined. These studies revealed, that during the 19781979 works, in an emergency situation and using rules and concepts of the time, retrofit techniques and materials were employed for the strengthening of the superimposed arcades, which caused the current state of damage detected.

The understanding of the structural behaviour was taken up, not only through a historical analysis of this sector of the monument, but also through modern investigation technique. To enable this, numerical analysis and in situ measurements were performed, in order to identify the crack pattern surveyed during the inspections.

The difficulties inherent to this analysis were mainly related to the importance of the Colosseum, which imposed a high rigor and critical sense of the various parameters analysed, as well as a careful understanding of the structural behaviour.

\footnotetext{
* Corresponding author
} 


\section{ANALYSIS OF THE PAST DAMAGES AND RETROFIT STRATEGIES OF THE COLUMNS}

The retrofitting interventions begun in early 1800 and were conducted in various parts of the Roman amphitheatre, in order to secure and to bring the monument back to its original form. The next few sections show the past damages and retrofit strategies of the travertine columns analysed, starting from this period.

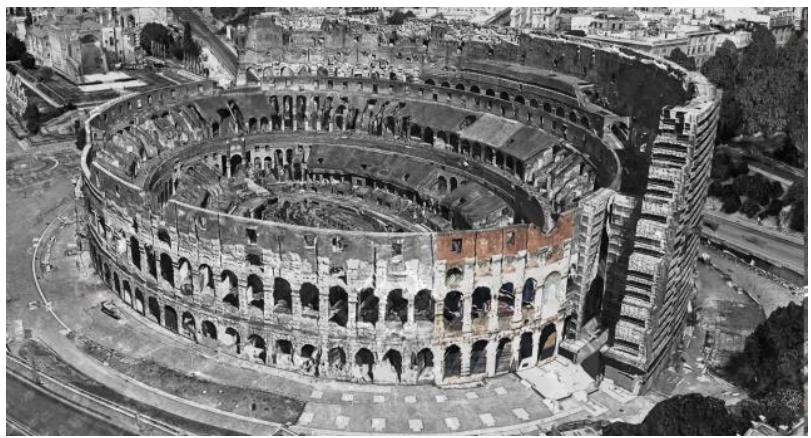

Figure 1. Photo of the eastern entrance of the Flavian Amphitheatre, in which the portion analysed is highlighted.

\subsection{Historical background of the Colosseum}

The construction of the Flavian Amphitheatre began around 70 $\mathrm{AD}$, as decided by the imperial family of the Flavians, from which it takes its name (Edmonson et al., 2005) and was completed ten years later. Post $500 \mathrm{AD}$ the original use of the Amphitheatre was discontinued and the structure was abandoned, leaving it to natural and anthropic damage (Luciani, 1993). This was until 1749, when Pope Benedict XIV (1740 - 1758) consecrated the arena to the memory of the Passion of Christ and his martyrs, declaring the monument a public church (Colagrossi, 1913).

From that moment onwards, a phase began, where a persistent, study, restoration and consolidation interventions were undertaken and have continued up until today.

\subsection{Restorations of the XIX centuries}

The reports produced by the architects of the early $19^{\text {th }}$ century provided an accurate description of the damage level of the arches and columns analysed (Guattani, 1815). This was testified by the 3D model made of cork by Carlo Lucangeli, between 1790 and 1812, on the state of conservation of the Flavian Amphitheatre at the end of the 18th century (Figure 2).

The early known retrofit interventions in this sector began in 1806, under the supervision of Raffaele Stern, with the construction of the large buttress, which even today cannot be missed. The purpose of this intervention was to prevent the collapse of the outer ring of the Amphitheatre which, having lost its continuity, caused the formation of plastic hinges and partial breaks of the arches, as well joint detachment between the travertine blocks. Later, another set of structural strengthening interventions, designed by Giuseppe Valadier, were performed directly on the columns analysed in this work around 1820 (Valadier, 1815). The instabilities were related to the overturning mechanism of the columns towards the outside, due to the collapse over the centuries of major portions of the outer ring of the Amphitheatre. This eliminated the thrust necessary for the balance of the structural system. Furthermore, the lack of connections between columns and radial walls, caused by the decay of materials (Coccia, 2005) and seismic events over the years (Croci, 1990), emphasized this behaviour.
The restoration work involved covering the columns of the first storey with travertine slabs, in order to increase the resistant section and to redefine the original geometry. Moreover, they introduced several metal ties to connect the columns to the radial walls and consolidated the existing holes and cracks with bricks and mortar (Figure 3).

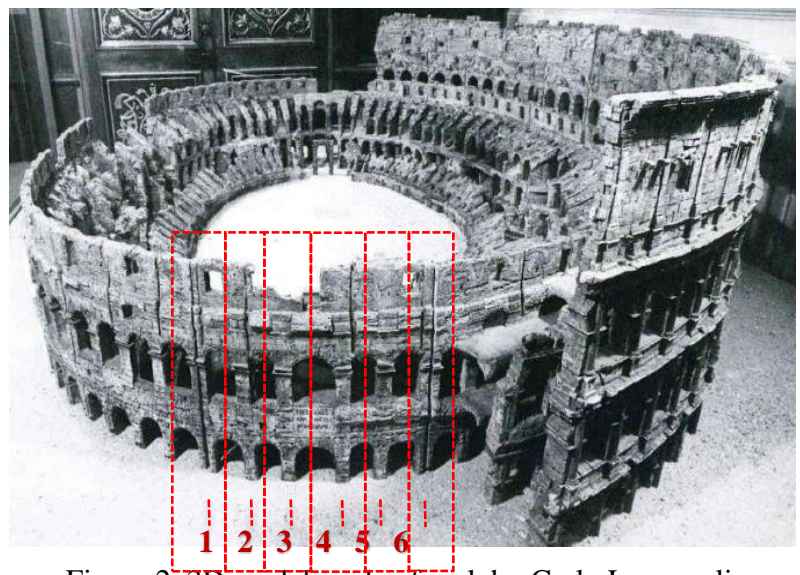

Figure 2.3D model mâdê of cork by Carlo Lucangeli.

In red the six columns, arranged in two storeys, under study are highlighted (Image taken from (Coarelli, 1999) p. 217).
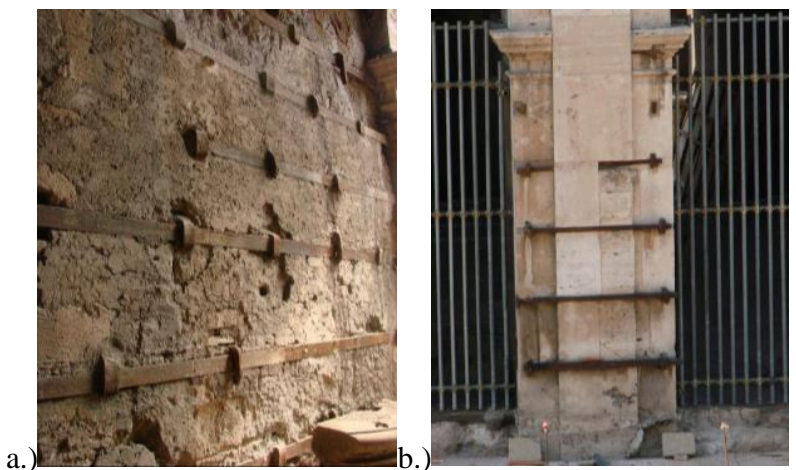

Figure 3. a.) Metal ties insert in the masonry wall behind the column to connect the travertine pillar; b.) Travertine slabs that cover the column and the metal ties insert in order to reduce the out of plane behaviour of the structure and for aesthetics aspects.

\subsection{Restorations of the year 1978 - 1979}

After the retrofit interventions of the XIX centuries no further damage was detected in this area of the amphitheatre, according to historical records, until mid-1970 when a travertine capital toppled over, introduced in the interventions of the nineteenth century. This highlighted the fractured nature of the column core. After removing the travertine slabs, used as a cover for the columns of the first floor, the cracks and damage were exposed, and examined (Figure 4).

The damage wasn't noticed only in the columns of the first floor, but also in those located in the second storey, although in a less widespread and intense manner (Figure 5).

The issues related to this new crack pattern according to the experts of the time, were attributed to the corrosion and rupture of some ties. Furthermore, the geometric irregularities of the walls reduced the contribution of the metal ties inserted in the nineteenth century, in addressing the out of plane behaviour of the façade (Croci, 1999). 
It was around the same time, when a drilling carried out near the columns up to a depth of 20 meters, confirmed the presence of a continuous foundation under the columns, and ruled out the collapse of the foundation as a structural issue. The vertical cracks detected on the columns were therefore attributed to the compression of the travertine blocks, due to the overturning of the facade, which was not addressed and when measured at the most inclined point of $64 \mathrm{~cm}$ (Figure 6).

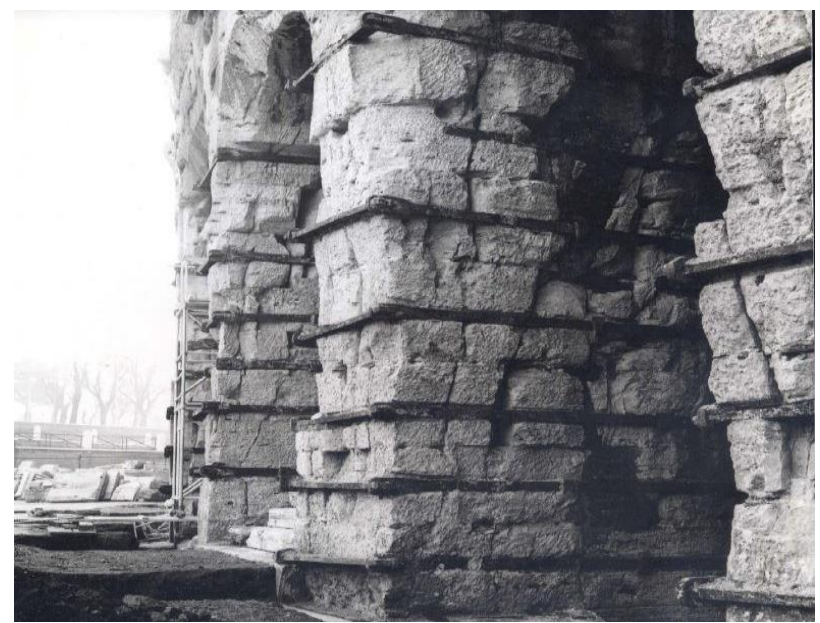

Figure 4. Image related to the retrofit interventions carried out in the 1970, that shows the state of the columns.

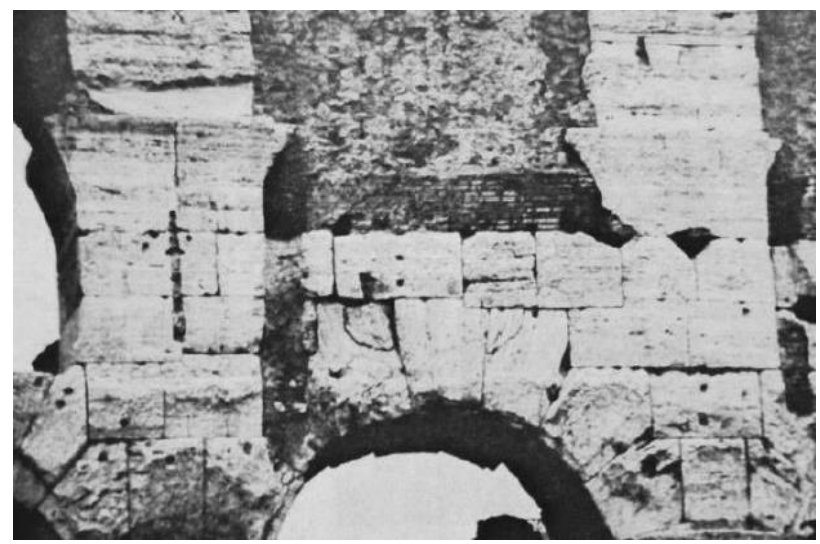

Figure 5. Detail of an arch of the second floor, where the sliding down of the key blocks was observed, as well as different cracks on the travertine blocks.

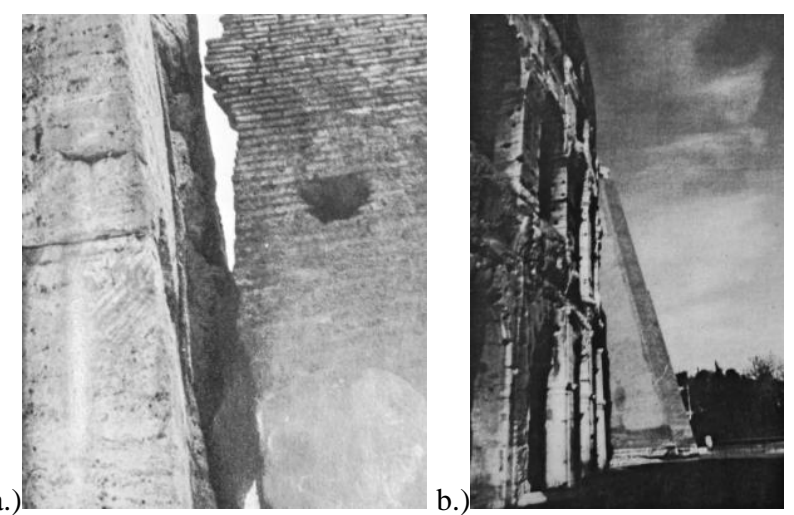

Figure 6. a.) Detachment of the travertine columns from the radial walls. b.) Out-of-plane behaviour of the façade from the North-west view of the analysed area.
The materials and techniques used in the retrofit intervention had the purpose of reducing the out-of-plane of the facade, closing the cracks and restoring continuity between the elements (Bulian, 1980).

The first phase of work started with a support system of the façade, achieved through steel tubes and the construction of masonry columns under the travertine arches of the first level (Figure 7). The mechanical characteristics of the travertine were verified by performing compression tests on two core samples (d $=120 \mathrm{~mm}$ ) taken from the façade. The first phase of the retrofit intervention took place with the filling of the cracks through twocomponent epoxy resin of araldite, mixed with stone (travertine) powder. Afterwards, a system of perforations $(\mathrm{d}=36 \mathrm{~mm})$ close one to each other and inclined at about $45^{\circ}$ in the columns and the arches in the transverse direction, were performed.

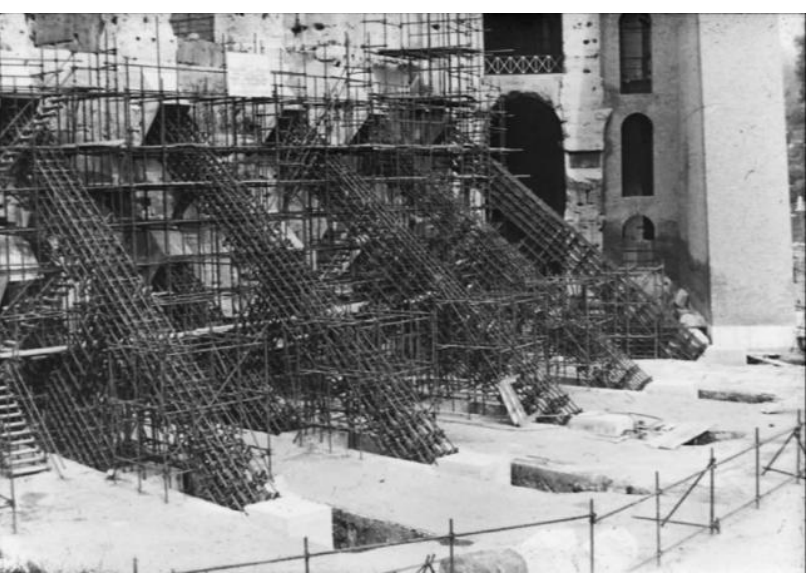

Figure 7. Construction of steel buttresses to prop up the columns of the first and second floors.

The distance between the perforations was not constant along the column and change from 1 to 1.5 hole per meter, for a total amount of around 20 crossing perforations for each column. A rebar was inserted into each hole and the injection of low-pressure epoxy resin was carried out, using copper pipes (Figure 8).
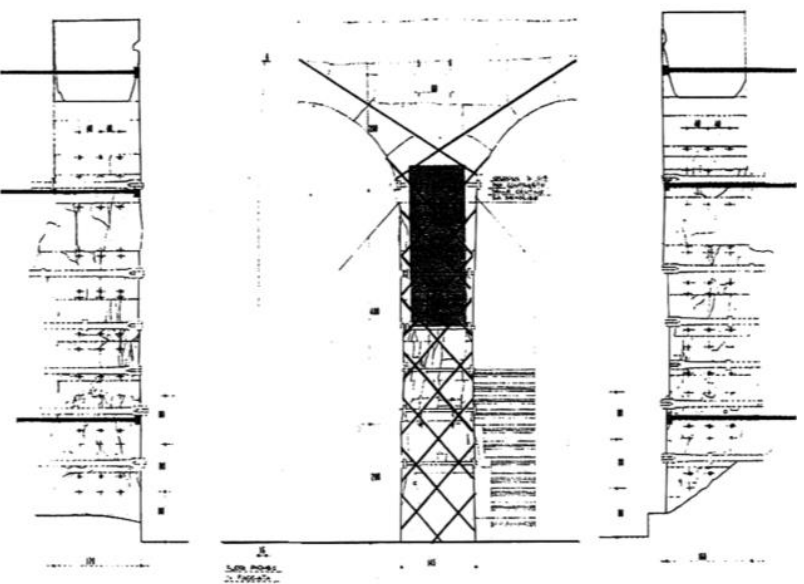

Figure 8. Drawing of the retrofit intervention project about the transversal and frontal perforations of the travertine columns and arches necessary for the insertion of the rebars.

In a second phase, the columns of the first floor were connected to the orthogonal masonry walls, through several harmonic steel cables $(\mathrm{d}=0.6 " \sim 15 \mathrm{~mm})$, inside a polyethylene sheath to allow a subsequent post - tensioning (Figure 9). 

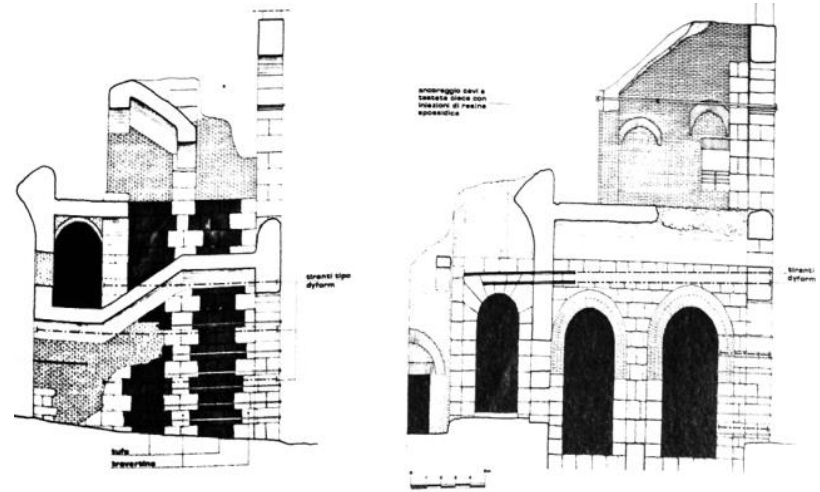

Figure 9. Drawings of the retrofit intervention project about the connection of the columns of the first floor with the orthogonal masonry walls.

For only two columns of the second floor, two post - tensioned cables were inserted vertically, in order to connect the travertine blocks along the entire length of the columns. The purpose of the two vertical post - tensioned cable was to decrease the thrust and to reduce the flexural compression stress at their base (Figure 10). This operation was carried out, because these two columns didn't have a wall behind them and therefore the out of plane behaviour of the façade can be avoided in this case by inserting metal ties, like for the other elements in the same floor.

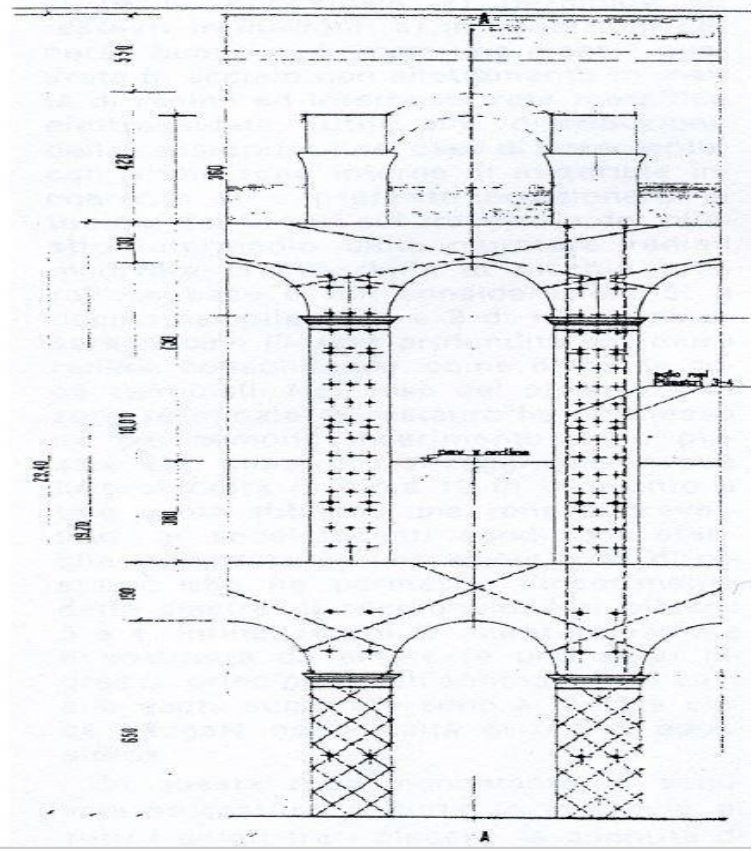

Figure 10. Drawings of the retrofit intervention project, with post - tension cables designed at the second level of the right column.

The third consolidation phase was carried out with the reconstruction of the columns section of the first level using epoxy resin mortar. The retrofit intervention was completed applying anticorrosive paint on the metal ties and with the placement of the travertine slabs of the nineteenth century to the columns of the first level, connecting them to the columns through steel bars (Figure 11). The special features of the monument increased the difficulty of this retrofit, for which new techniques were performed and where the chemical and physical behaviour between old and new repair material was difficult to forecast.
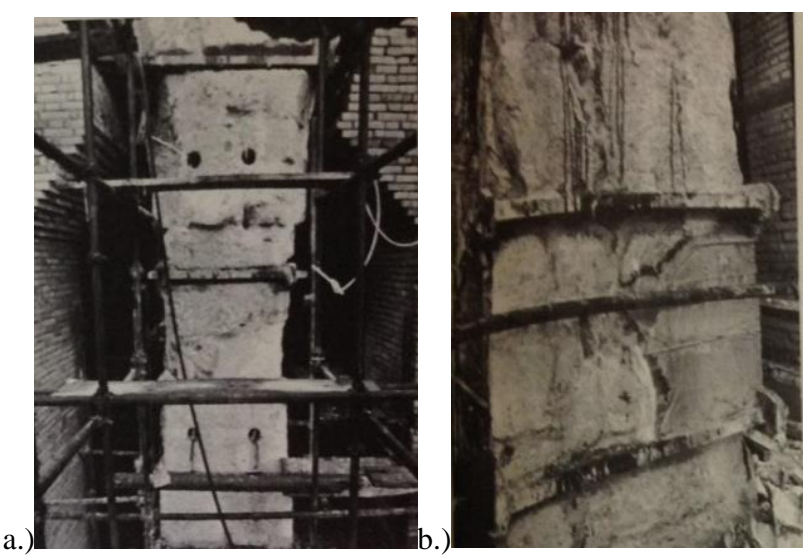

Figure 11. a.) Image of the harmonic steel cables in the travertine columns during the phase of work. b.) Reconstruction of the pillar section with epoxy resin and travertine pieces.

\section{CURRENT DAMAGE DETECTION OF THE COLUMNS}

The events of 1978 and 1979 showed the fragilities of the Flavian Amphitheatre and highlighted the need to carry out new surveys, in order to prevent instability and to guarantee the safety of the monument (Bocchi, 2014).

During the restoration of the external ring of the Flavian Amphitheatre, begun in 2012, new cracks were observed in this sector of the monument and therefore it was decided to carry out a more detailed analysis. The following chapters contain the analysis and studies of this sector realized after different site inspections between November 2015 and March 2016 (Figure 12).

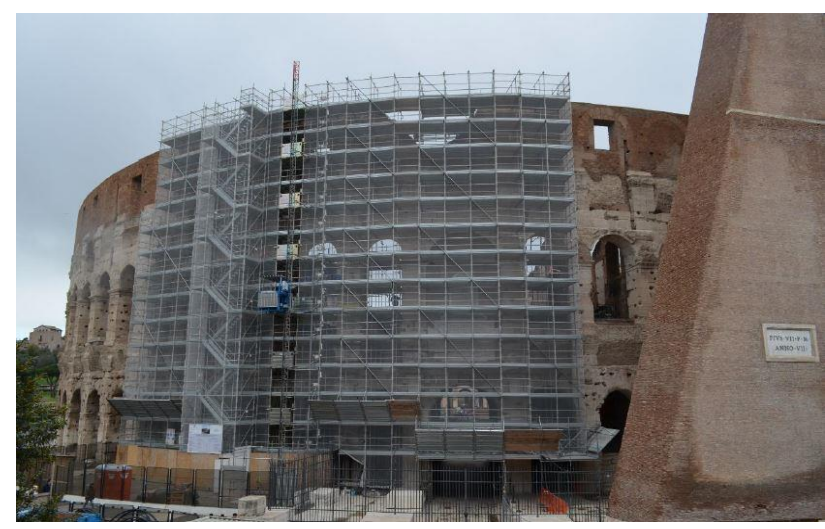

Figure 12. Construction site for the study of the columns affected by the current damage.

\subsection{Out of plane behaviour of the façade}

Bearing in mind the cause of the structural problems related to this area of the Flavian Amphitheatre, a new control of the out of plane facade behaviour was performed, comparing the data collected during the study of the interaction between the monuments and the new $\mathrm{C}$ line of the underground under construction (AA.VV., 2009), with the information of the inspections carried out by the authors.

Figure 13 shows the out of plane behaviour of the façade, expressed as a light blue vector perpendicular to front, and defines the horizontal displacement in centimetres. The length of the vector corresponds to the intensity of the displacement. 


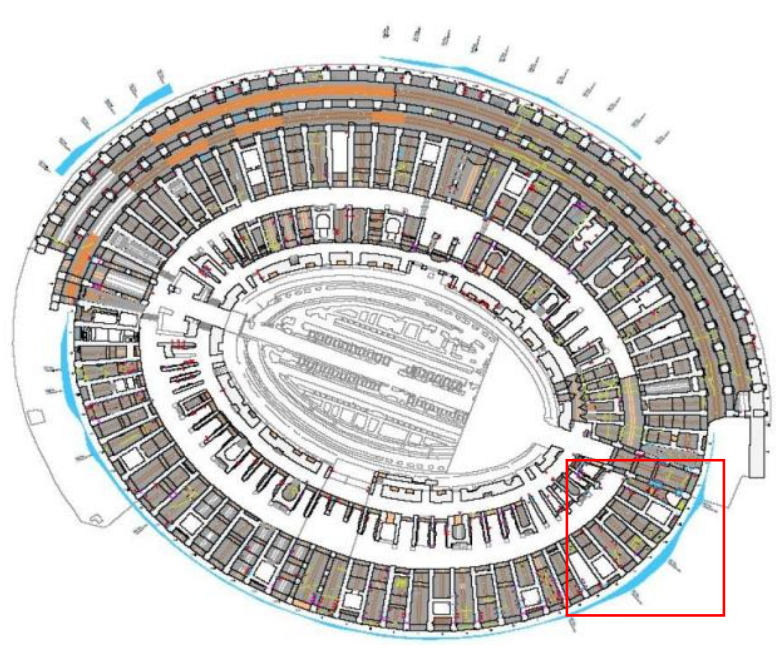

Figure 13. In red the area analysed is highlighted, while the out of plane intensity of the façade is shown in light blue colour.

(Image taken from the analyses performed for the construction of the new $\mathrm{C}$ line of the underground under construction

(AA.VV., 2009).

The value of the out of plane of the columns analysed, were expressed in with respect to the height of structure (Table 1). The most critical cases regarding the out of plane concerned columns 1 and 2 (Figure 14). As is shown in the subsequent crack pattern, these columns were on average less damaged than the other columns surveyed, which suggested that the cause of the new cracks detected was not strictly attributable to this phenomenon.

\begin{tabular}{|c|c|cccccc|}
\hline Height & Floor & Pil. 1 & Pil. 2 & Pil. 3 & Pil. 4 & Pil. 5 & Pil. 6 \\
\hline $29,15 \mathrm{~m}$ & I & 10 & 13 & 6 & 3 & 8 & 0 \\
$36,30 \mathrm{~m}$ & II & 23 & 26 & 18 & 8 & 24 & 0 \\
$43,10 \mathrm{~m}$ & III & 36 & 26 & 21 & 21 & 34 & 5 \\
$52,40 \mathrm{~m}$ & Roof & 51 & 46 & 43 & 21 & 21 & 8 \\
\hline
\end{tabular}

Table 1. Out of plane displacement $(\mathrm{cm})$ of the columns analysed.

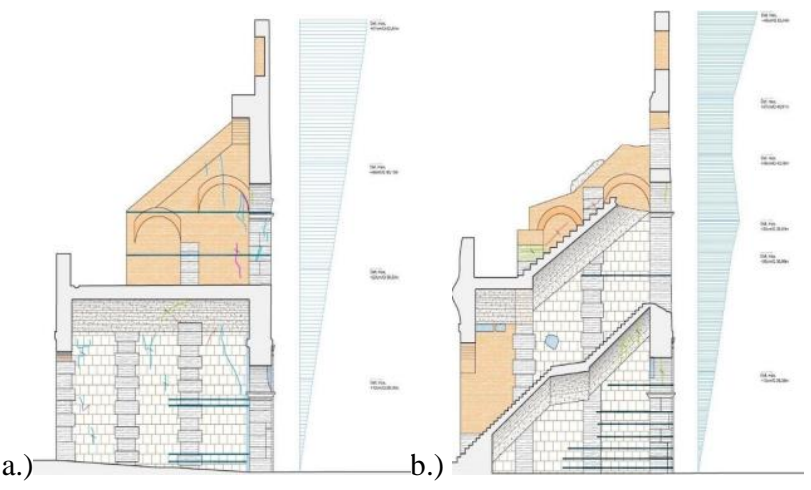

Figure 14. a.) Out of plane measured along the height of column 1 ; b.) Out of plane measured along the height of column 2 .

(Images taken from the analyses performed for the construction of the new $\mathrm{C}$ line of the underground under construction (AA.VV., 2009))

Furthermore, the material used, during the works of 1978 and 1979 , to fill the gaps between the columns and the masonry walls behind them, didn't show any detachment or sliding phenomena. This further aspect helped to understand the current crack pattern detected during the actual inspections.

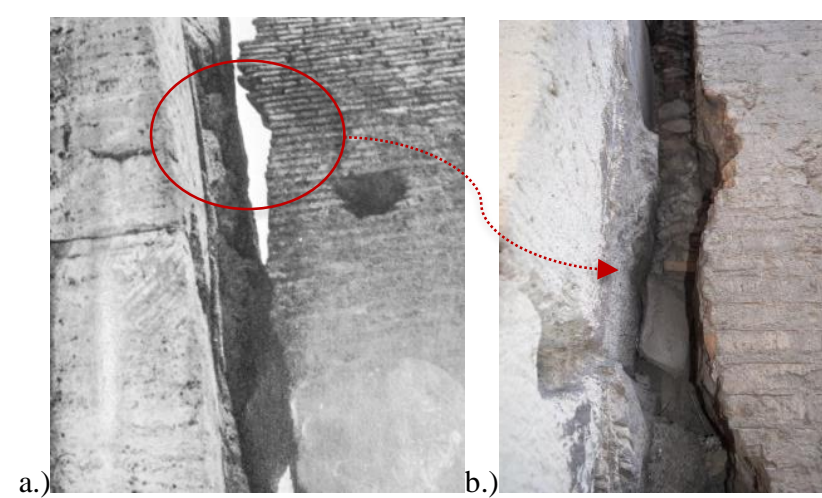

Figure 15. a.) Image taken during the retrofit interventions of 1978 and 1979; b.) Photo taken during the 2015-2016 surveys from the same point of view.

The out of plane behaviour of the façade was also analysed by checking the decay state of the nineteenth-century ties, as well as the masonry walls, in which they were anchored in (Figure 16). The elements were substantially in good condition and didn't show an advanced state of degradation or cracking, except in some cases, where the ties had cracks at their extreme ends that could have arisen, due to the forging process (Podestà et al, 2012). The crack pattern detected on the walls was not related to the damage of the columns, but to their base movement.

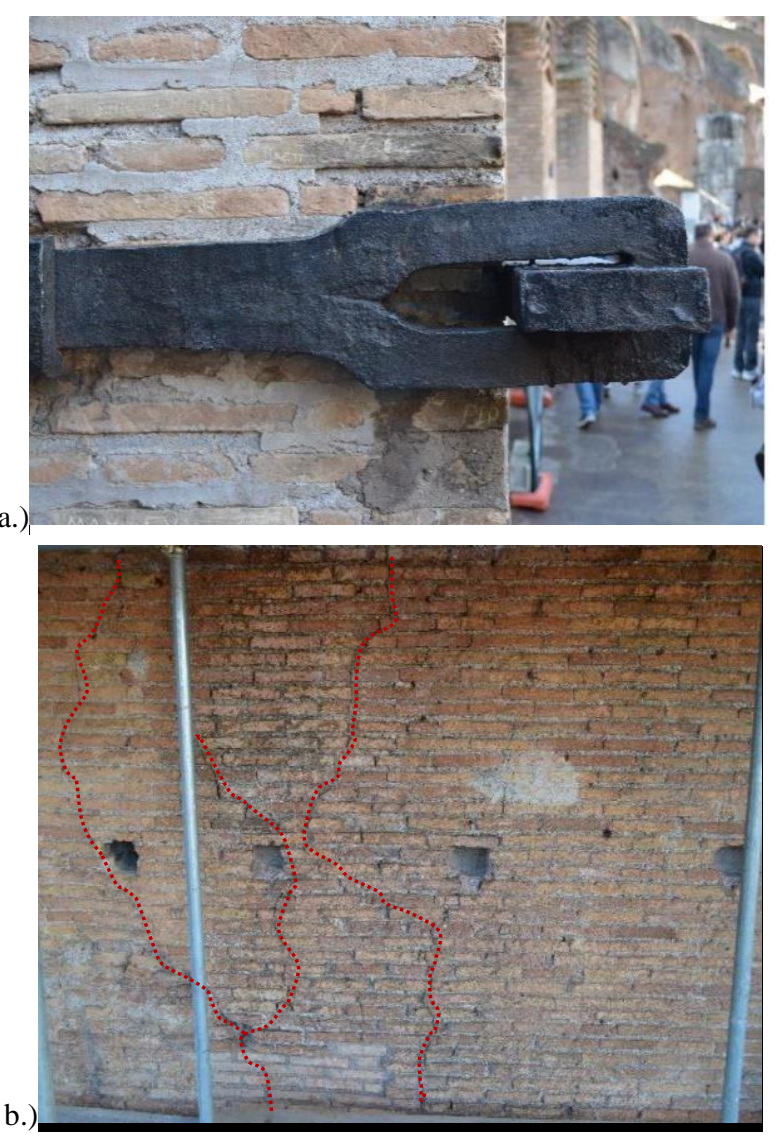

Figure 16. a.) Metal ties on the second floor, that connect column 1 with the masonry orthogonal wall; b.) Crack pattern, highlighted in red, of the same masonry wall at the first floor. 


\subsection{Crack pattern survey}

A crack model was prepared based on a detailed visual survey, supported by high resolution photographic documentation using a digital camera, identifying the external damage visible on the facade.

The purpose of this work was therefore to identify the main visible cracks present on the travertine columns and to accurately map their location, giving an overall view on the state of decay present. The numerical information on the dimensions and location of the cracks, acquired during the survey, was subsequently processed using CAD programs (Figure 17). From a qualitative and morphological point of view, the cracks were subdivided according to their width $(\omega)$, following to a comparative criterion:

- Capillary Cracks (D0): $\omega<0.5 \mathrm{~mm}$

- Micro-cracks (D1): $0.5 \mathrm{~mm}<\omega<1 \mathrm{~mm}$

- Damage (D2): $1 \mathrm{~mm}<\omega<2 \mathrm{~mm}$

- Macro-cracks(D3): $\omega>2 \mathrm{~mm}$

The perforations and core drills carried out in the retrofit of 1978 and 1979 were identified in the drawings through circles of different colours (Figure 18).

The same damage characterized by sub-vertical cracks, that cross the holes in which the rebars were inserted, was also detected in the internal part of the arches that connect the different columns (Figure 19).

Table 2 indicates the damage distribution of the columns detected during the survey. In Column 3 and 4 was concentrated the greatest crack pattern, while column 1 and 6 showed the less damage.

\begin{tabular}{|c|cccc|}
\hline Column & D0 & D1 & D2 & D3 \\
\hline 1 & $\sqrt{ }$ & $\sqrt{ }$ & & $\sqrt{ }$ \\
2 & $\sqrt{ }$ & $\sqrt{ }$ & $\sqrt{ }$ & \\
3 & $\sqrt{ }$ & $\sqrt{ }$ & $\sqrt{ }$ & $\sqrt{ }$ \\
4 & $\sqrt{ }$ & $\sqrt{ }$ & $\sqrt{ }$ & $\sqrt{ }$ \\
5 & $\sqrt{ }$ & $\sqrt{ }$ & $\sqrt{ }$ & \\
6 & $\sqrt{ }$ & $\sqrt{ }$ & & \\
\hline
\end{tabular}

Table 2. Damage distribution on the façade analysed
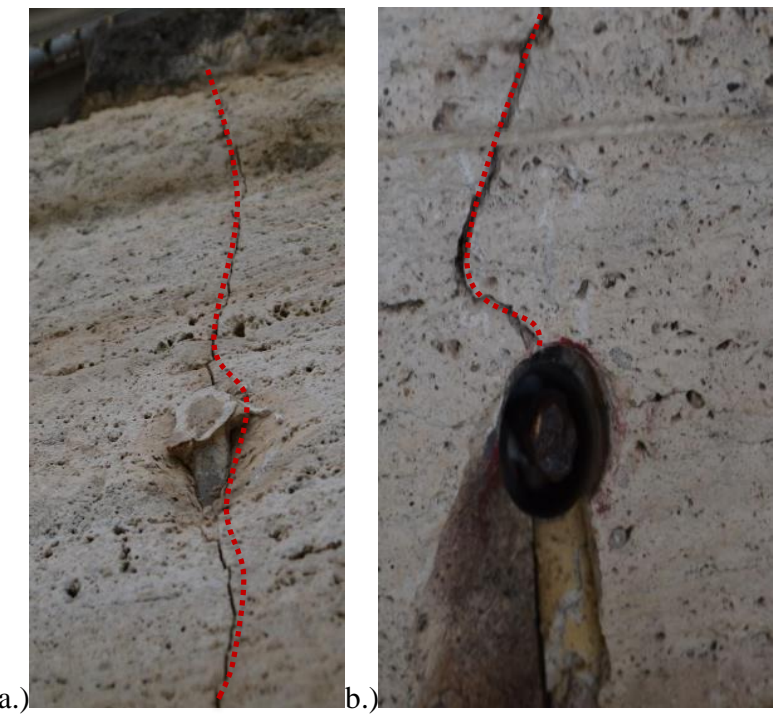

Figure 18. a.) Rebar coming out from the original position, inside of the travertine column and crossed by a sub - vertical crack; b.) Image of the metal bar inside the pillar after removing the cap made by epoxy resin and travertine pieces.

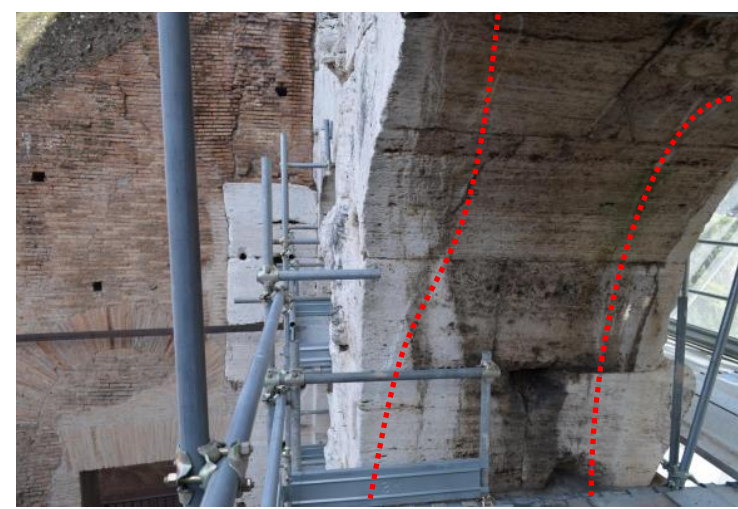

Figure 19. Vertical cracks, highlighted in red, in the internal part of the arch between column 4 and 3 .

A core drilling, performed in column 3, showed that the rebars were corroded not only in the external, but also in the inside.

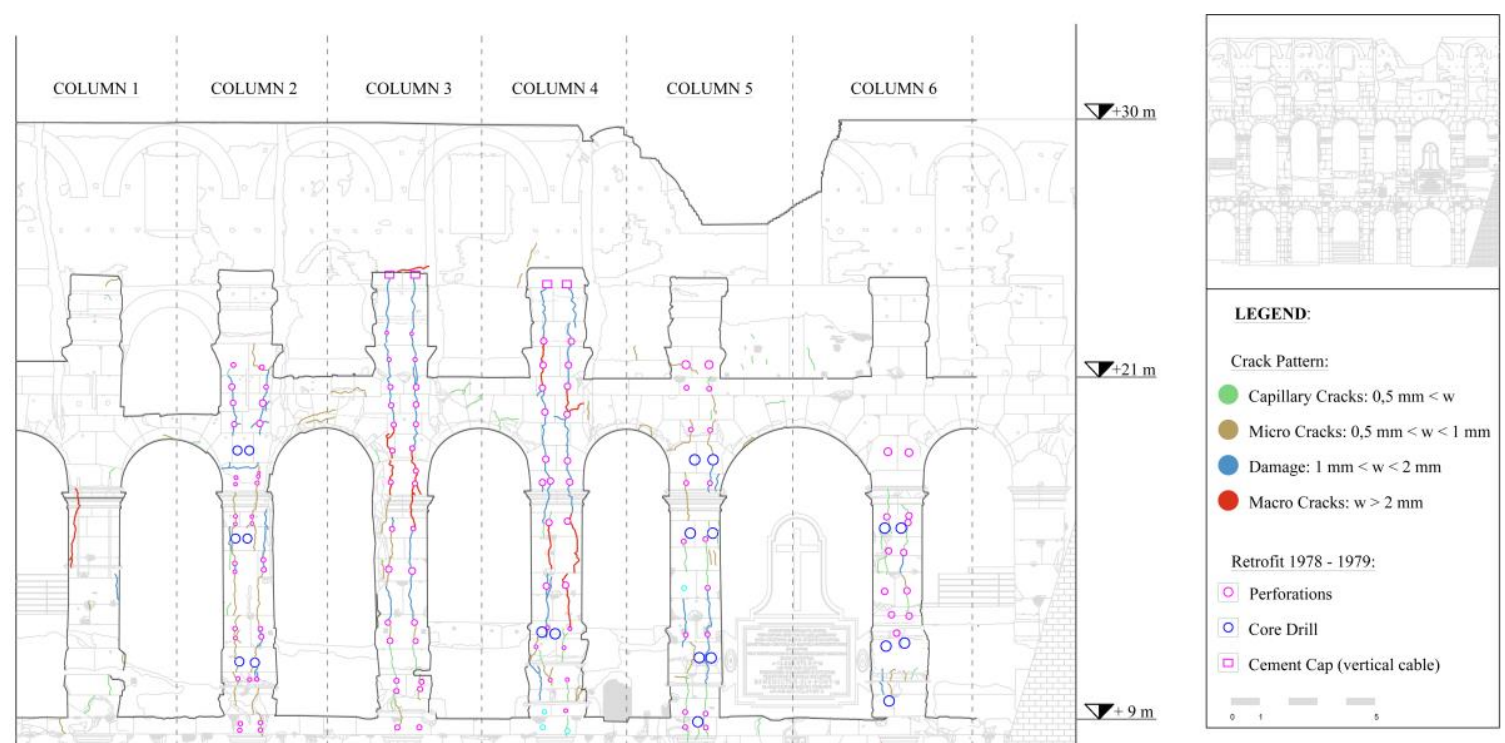

Figure 17. Crack pattern of the travertine columns at the second floor from the external point of view. 
This intervention gave the possibility to check the slope of the steel elements and after defining the position of each rebars' hole detected in the columns, it was possible to define the internal disposition of the rebars through a 3D Model (Figure 20).

a.)

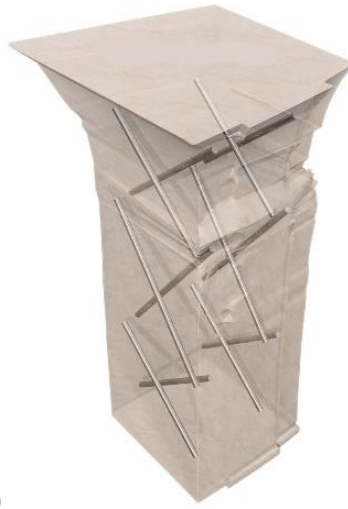

b.)

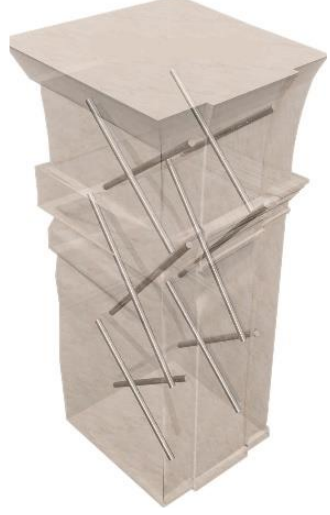

Figure 20. a.) 3D Model of column 2 with rebar disposition; b.) 3D Model of column 3 with rebar disposition.

While the travertine structure was visible in the second floor, in order to control the decay state of the columns of the first floor, some travertine slabs of Valadier's intervention were removed. In this case, the cracks detected had a smaller width and were less widespread, in respect to the ones surveyed in the second floor (Figure 21).

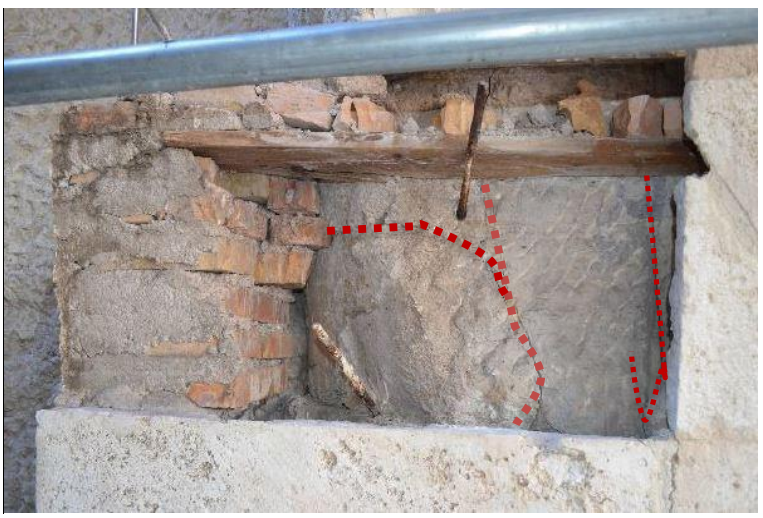

Figure 21. Cracks detected and highlighted in red on the columns of the first floors after removing the travertine slabs in pillar 5.

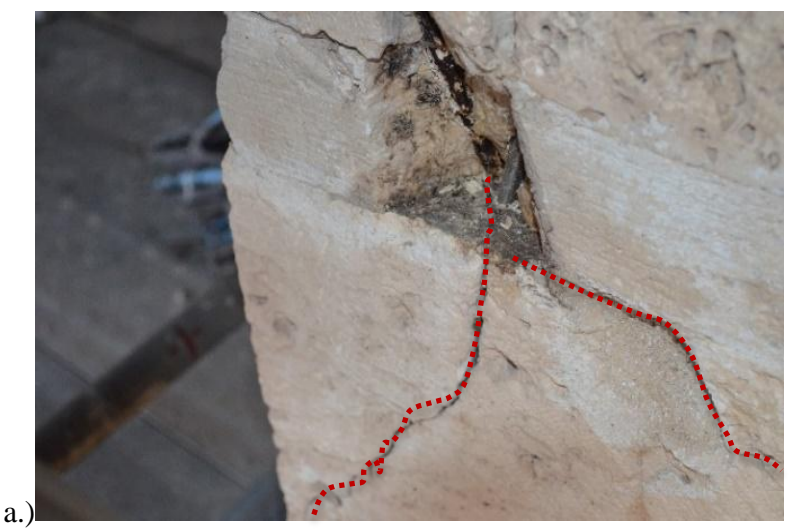

b.)

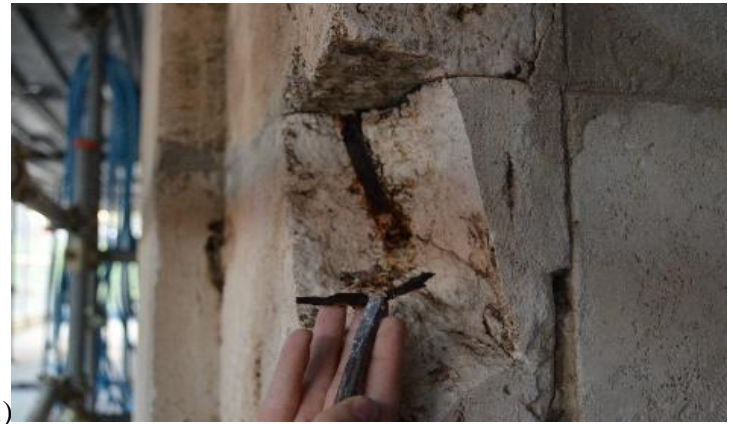

Figure 22. Damage, highlighted in red, caused by the corrosion of the bars, employed for fixing the travertine slabs in the retrofit interventions of 1978 e 1979 in column 3 left corner (a) and right corner (b)

The most dangerous damage detected at the first floor was characterized by the corrosion of the metal bars employed in the 1978-1979 retrofit interventions for fixing the travertine slabs on the columns. The corrosion of these elements caused fractures in parts of travertine stone (Figure 22).

The horizontal post tensioned cables inserted in the first floor (Figure 9) were not monitored since the exposed columns and the walls behind them showed no visible damage. A test was performed in the third column at the second level, where a vertical post tensioned cable was inserted (Figure 23). Here the cracks detected had the highest dimension (Table 2). After removing the concrete cap of the upper part, in order to check the internal conditions, it was noted that the cable inside was less corroded and the cable sheath didn't show clear signs of wear or degradation. It was not possible to investigate further parts inside the column, to check the corrosion of the post-tensioned cable.
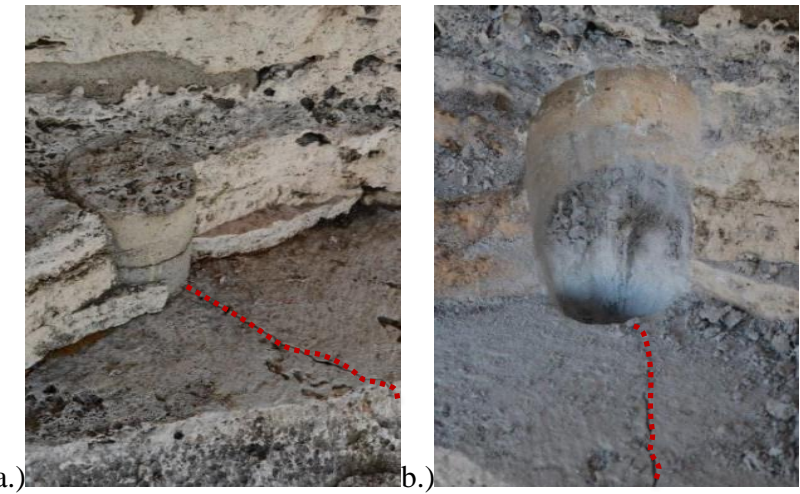

Figure 23. a) Cement cap of the post tensioned cable positioned on the top of column 3 with crack highlighted in red; b.) Post tensioned cable after removing the cement cap.

\subsection{Discussion of the results}

The geometrical and technological survey of the façade showed a crack pattern defined by vertical cracks in the column of the second floor, passing through the holes, in which the rebars were inserted in the retrofit intervention of 1978-1979. This situation was even worse for columns number 3 and 4, which didn't have an orthogonal masonry wall behind them on the second floor, and where vertical post tensioned cables were inserted. The study of the façade's out-of-plane behaviour showed that even the most inclined columns (columns 1 and 2) were the least damaged, and therefore the damage detected cannot be related to the overturning of the front. 
The analyses performed in the field of the fracture mechanics (Kirsch, 1898), (Andreeva et al., 2014), suggested that the vertical cracks were caused by the presence of a radial force inside the rebars' holes (Romis, 2010). These studies showed also, that the size of the vertical cracks increased if a vertical component was added to the radial tension of the hole. The corrosion of the steel bars inside the columns can lead to that crack pattern and to the worsen damage detected the column 3 and 4 in the second floor, caused by the presence of the posttensioned vertical cables.

The travertine slabs of the first floor's columns, introduced by Valadier's intervention, presented serious damage with detachment of blocks caused, also in this case, by the oxidation of the metal bars inserted for their repositioning, during the retrofit of 1978-1979. Finally, the masonry walls and the metal ties of the XIX centuries restorations were in good conditions and no damage was detected.

\section{CONCLUSION}

This article presents a study of a sector of the Flavian Amphitheatre, in Rome, characterized by a significant crack pattern and widespread damage on six travertine columns.

The principal vulnerability of the façade was determined by the out of plane behaviour, caused by the absence of the external ring of the monument, collapsed and dismantled during the centuries. This issue was avoided through the XIX centuries and 1978-1979 restorations, that stopped the instability evolution of the façade.

The absence of stainless or galvanized steel used during the retrofit of 1978 - 1979, in a chemically aggressive environment, like the densely populated roman urban centre, was the principal cause of the recent state of degradation of this sector of the Colosseum.

Bearing in mind the concepts of modern conservation systems, the 1978/79 interventions were carried out, preserving the architectural integrity of the monument, but neglecting the issues related to the reversibility and above all the durability of the materials employed. In some circumstances, the intervention is also considerably invasive and disproportionate to the context and causes of the failure, as it has been possible to detect and analyse, especially in the second order of the façade.

The limit of these studies can be attributed to the fact that no exploitable samples were taken for examination from the damaged columns, which could have provided more precise results. In the same way, it was not possible to carry out surveys in the ground, to understand the state of the foundation of the Flavian Amphitheatre in that sector, necessary to better understand the main critical issues of the façade: the out of plane behaviour. However, the choice not to perform this type of intervention was decided to avoid invasive tests, that would have broken an already damaged part of the monument.

The importance of these studies was directly linked to the uniqueness of the monument both from a cultural, intellectual and engineering point of view, whose conservation over time for future generations represented a duty for the current ones.

\section{ACKNOWLEDGEMENTS}

Acknowledgements of support to the Parco Archeologico del Colosseo - Rome, in the person of Dott.ssa Rossella Rea and Arch. Barbara Nazzaro.

\section{REFERENCES}

AA.VV., 2009. Studio di interazione linea - monumenti. Relazioni tecniche di sintesi per la costruzione della Metropolitana di Roma Linea $\mathrm{C}$, Rome.

Andreeva, V.I., Cybina, N.Y., 2014. The Inhomogeneous Plate with a Hole: Kirsch's Problem. Vol. XXIII R-S-P seminar, Theoretical Foundation of Civil Engineering (23RSP).

Bocchi, M., 2014: Centri storici, restauro urbano e archeologia: il caso studio della legge Biasini (1981). Master Thesis of the Polytechnic of the University of Turin.

Borri, A., Sisti, R., Zaroli, A., Prota A., Di Ludovico M., De Maria, A., 2018. Gli edifici di Campi Alto di Norcia di Norcia nel sisma del 2016. Diversità nella risposta sismica di costruzioni consolidate in anni recenti. Structural.

Bulian, G., 1980. Resine epossidiche per il consolidamento di sei pilastri dell'anfiteatro Flavio. L'industria tecnica delle costruzioni, A.N.C.E, 99. - 1980. - p. 13-24.

\section{Coarelli, F., 1999. Il Colosseo. Electra, Milan.}

Coccia, S., Como, M., Ianniruberto, U., Conforti, M.L., 2005: On the reasons of the Colosseum structural damage. Seminar Theory and Practice of Construction: Knowledge. means, models, p. 27-29, Ravenna.

Colagrossi, P., 1913: L'Anfiteatro Flavio nei suoi 20 secoli di storia. HardPress Publishing, Rome.

Croci, G., 1990 Studi e ricerche sul Colosseo. Dipartimento di Ing. Strutt. e Geot., Rome.

Croci, G., 1999. Modello numerico del versante settentrionale dell'Anfiteatro Flavio e schema della deformazione radiale e sollecitazioni corrispondenti. Disegnare, Idee Immagini, p. 18-19.

D'Altri, A.M., et al., 2019. Numerical Modelling of Masonry and Historical Structures. From Theory to Application (Chapter 1), Bahman Ghiassi and Gabriele Milani, Vol. Woodhead Publishing Series in Civil and Structural Engineering.

Edmonson, J.F., Mason, S., Rives, J.B., 2005. Flavius Josephus and Flavian Rome. Oxford University Press, London.

Giuffrè, A., 1993. Sicurezza e conservazione dei centri storici. Il caso di Ortigia, Editore Laterza, Rome.

Guattani, G.A., 1815. Appunti. Archivio dell'accademia di San Luca, Vol. 86, n 78 , Rome.

Kirsch, E.G., 1898. Die Theorie der Elastizität und die Bedürfnisse der Festigkeitslehre, Zeitschrift des Vereines deutscher Ingenieure. Vol. 42, pp. 797-807.

Luciani, R., 1993. Il Colosseo, Fenice 2000, Rome.

MIBACT, 2010. Linee Guida per la valutazione e riduzione del rischio sismico del patrimonio culturale allineate alle nuove Norme tecniche per le costruzioni (D.M. 14.01.2008). Circolare n.26 Ministero per i Beni e le Attività Culturali, Rome.

Podestà, S., Scandolo, L., 2012. Affidabilità delle catene metalliche nell'edilizia storica. Vol. Progettazione Sismica, vol.I pp. 67-78.

Romis, F., 2010. Interventi di consolidamento sul patrimonio culturale: L'Anfiteatro Flavio a Roma. Master Thesis of the University of Genoa.

Valadier, G., 1815. Appunti. Archivio dell'accademia di San Luca, Vol. 86, n 78 , Rome. 